\title{
Insights in the Nutrigenetic, New Candidate Genes in Nutritional Diseases (Lrp2, Cubn, Amn, Atxn2, Tjp1, Elmo1)
}

\author{
Diego Ortega-Pacheco ${ }^{1}$, Perla Ruiz Madrigal ${ }^{2}$, Erick Ramirez-Bohórquez ${ }^{1}$, Luis Javier Flores Alvarado ${ }^{2}$, Rosalba Ruiz- \\ Mejía $^{2}$, Sergio Alberto Ramirez-Garcia ${ }^{3 *}$ \\ ${ }^{1}$ Programa de Maestría en Salud Pública, Universidad de la Sierra Sur, Miahuatlán de Porfirio Díaz, Oaxaca, México \\ ${ }^{2}$ Laboratorio de Bioquímica, Departamento de Biología molecular y Genómica, CUCS, Universidad de Guadalajara, Jalisco, México \\ ${ }^{3}$ Instituto de Investigaciones sobre la Salud Pública, Universidad de la Sierra Sur, SUNEO, Miahuatlán de Porfirio Díaz Oaxaca, México
}

\section{Introduction}

There is a group of diseases which are taking focus in nutrition, since they are related to the deficiency of the vitamin B complex; particularly cyanocobalamin and folic acid; such as neural tube defects, congenital heart disease, hyperhomocystinemia, anemia with albuminuria, peripheral neuropathies, primary or secondary megaloblastic anemia, and dyslipidemia, among others. These clinical phenotypes are related to variants in the transport system at the intestinal as well as renal level for these vitamins; the transcription system mediated by megalin, cubilin, the protein aminols, among others (which are encoded by the LRP2, CUBN and AMN genes). Mutations in CUBN, AMN produce a syndrome with albuminuria and anemia. This may be explained since cyanocobalamin binds to these two factors to be endocytosed at the intestinal level as well as in the proximal convoluted tubule. But it also determines the absorption of complex b, so when there is a deficit of these proteins or alterations in its structure translates into megaloblastic anemia [1]. Functional polymorphisms (coding region, cryptic sites, introns, promoter or enhancer) become important in the nutritional management of microcytic, megaloblastic or pluricarential anemia. However, there is no study that establishes the relationship between diet and response to treatment in relation to anemia.

From the nutrigenetic it is important to analyze all platforms of genetic variants both mutations and polymorphisms to estimate and predict the severity of the phenotype of all the above mentioned diseases, as well as to evaluate the impact of these polymorphisms in the response to clinical and nutritional treatment. This field has not yet been explored.

Another target that deserves attention is the gene encoding for close binding 1 (TJP1), and the one encoding for ataxin-2 (ATXN2). The former seems to be a regulator of the intestinal, renal and endothelial flow of triglycerides and cholesterol [2], so its genetic variants are not only related to the development of dyslipidemia but also have to be predictive of the response to nutritional treatment. ATXN2 has a pleiotropic effect and is considered a nutritional modulator sensitive to cellular stress, in a knock-out model, the liver of the mice presents significant decrease of proteins related to the oxidation of fats, degradation of branched amino acids, ketogenesis and cycle of citric acid [3]. And on the other hand in humans, the ATXN2 gene are involved in abnormalities related to insulin resistance; Obesity, alterations in lipid metabolism, hypertension, disorders of glucose homeostasis, severe polyphagia, among other inflammatory and vascular metabolic features [4-5], this is explained, since at the cellular level regulates insulin signaling, through GRB2; With these considerations is a candidate to analyze the influence on the response to nutritional treatment of chronic degenerative diseases mentioned above in this paragraph, which are directly influenced by diet, and diet is a pillar in their clinical treatment.

\section{Publication History:}

Received: May 25, 2017

Accepted: June 28, 2017

Published: June 30, 2017

\section{Keywords:}

Atanxin-2, Cubilin, Megalin, Anemia megaloblastic, Celiac disease

Finally a gene that would be worth analyzing is the gene ATXN2 and ELMO1 especially in wheat intolerance, which is the cause of celiac disease (CD). ATXN2 by ligation studies has been implicated in celiac disease; the SNP (rs653178 at the SH2B3/ATXN2 locus) displayed study-wise statistically significant association with directionality consistent effects on $\mathrm{CD}[6]$. Previously reported by genetic linkage analyses, genome-wide association studies of single nucleotide polymorphisms, copy number variation surveys, and mutation screenings found the human chromosomal 12q24 locus, with the genes SH2B3 and ATXN2 in its core, to be associated with an exceptionally wide spectrum of disease susceptibilities neurodegenerative, cardiovascular and autoimmune disease, among them, celiac disease [7]. For association study the marker SNP rs653178, in the ATXN2 gene is associated with CD [8]. While ELMO1 has not yet been explored; but may play a role since ELMO1 is a regulator of inflammation and fibrogenesis through TGFB1 [9]. The variants of these genes have not been explored yet even in celiac disease in relation to the response to clinical and nutritional treatment.

\section{Competing Interests}

The authors declare that they have no competing interests.

\section{References}

1. Flores-Alvarado LJ, Villafán-Bernal JR, Cabrera-Pivaral CE, Castro J Ramirez-Garcia SA (2017) Exploration of gene variations in the transcytosis system as a policy proposal for the personalized therapy in type 2 diabetes mellitus. J Med Therap 1: 1-3.

2. Ramirez-Garcia SA, Flores-Alvarado LJ, Topete-González LR, CharlesNiño C, Mazariegos-Rubi M, et al. (2016) High frequency of ancestral allele of the TJP1 polymorphism rs2291166 in Mexican population, conformational effect and applications in surgery and medicine. Cir Cir 84: 28-36.

"Corresponding Author: Dr. Sergio Alberto Ramirez Garcia, Calle Guillermo Rojas Mijangos S/N, Esq. Av. Universidad Col. Ciudad Universitaria, Miahuatlán de Porfirio Díaz, Oaxaca., México C.P. 70800; E-mail: sergio7gentica@hotmail.com

Citation: Ortega-Pacheco D, Madrigal PR, Ramirez-Bohórquez E, Alvarado LJF, Ruiz-Mejía R, et al. (2017) Insights in the Nutrigenetic, New Candidate Genes in Nutritional Diseases (Lrp2, Cubn, Amn, Atxn2, Tjp1, Elmo1). Int J Clin Nutr Diet 3: 120. doi: https://doi.org/10.15344/2456-8171/2017/120

Copyright: () 2017 Ortega-Pacheco et al. This is an open-access article distributed under the terms of the Creative Commons Attribution License, which permits unrestricted use, distribution, and reproduction in any medium, provided the original author and source are credited. 
Citation: Ortega-Pacheco D, Madrigal PR, Ramirez-Bohórquez E, Alvarado LJF, Ruiz-Mejía R, et al. (2017) Insights in the Nutrigenetic, New Candidate Genes in Nutritional Diseases (Lrp2, Cubn, Amn, Atxn2, Tjp1, Elmo1). Int J Clin Nutr Diet 3: 120. doi: https://doi.org/10.15344/2456-8171/2017/120

3. Meierhofer D, Halbach M, Şen NE, Gispert S, Auburger G (2016) Ataxin-2 (Atxn2)-Knock-Out Mice Show Branched Chain Amino Acids and Fatty. Mol Cell Proteomics 15: 1728-1739.

4. Lastres BI, Brodesser S, Lütjohann D, Azizov M, Buchmann J, et al. (2008) Insulin receptor and lipid metabolism pathology in ataxin-2 knock-out mice. Hum Mol Genet 17: 1465-1481.

5. Lastres $\mathrm{BI}$, Nonis $\mathrm{D}$, Eich $\mathrm{F}$, Klinkenberg $\mathrm{M}$, Gorospe $\mathrm{M}$, Kötter $\mathrm{P}$, et al (2016) Mammalian ataxin-2 modulates translation control at the preinitiation complex via PI3K/mTOR and is induced by starvation. Biochim Biophys Acta 1862: 1558-1569.

6. Jansen H, Willenborg C, Schlesinger S, Ferrario PG, König IR, et al. (2015) Genetic variants associated with celiac disease and the risk for coronary artery disease. Samani NJ, Lieb W, Schunkert H. Mol Genet Genomics 290: 1911-1917.

7. Auburger G, Gispert $\mathrm{S}$, Lahut $\mathrm{S}$, Omür $\mathrm{O}$, Damrath $\mathrm{E}$, Heck $\mathrm{M}$, Başak N (2014) 12q24 locus association with type 1 diabetes: SH2B3 or ATXN2?. World J Diabetes 5: 316-327.

8. Hinks A, Martin P, Flynn E, Eyre S, Packham J, et al (2010) Investigation of type 1 diabetes and coeliac disease susceptibility loci for association with juvenile idiopathic arthritis. Ann Rheum Dis 69: 2169-2172.

9. Topete-González LR, Ramirez-Garcia SA, Charles-Niño C, Villa-Ruano N, Mosso-González C, et al. (2014) Polymorphism g.37190613 G>A of the ELMO1 gene in the Mexican population: potential marker for clinicalsurgical pathology. Cir Cir 82: 402-411. 